do, según la metodología personal del maestro Tamura, en perfecta simbiosis con la tradición y las formas contemporáneas de enseñanza de las artes corporales, así como de los requisitos o normas que ha de guardar el principiante en el ámbito físico, mental y social.

A partir de aquí el autor aborda las reglas mas elementales de cortesía, respeto y etiqueta que forman parte inseparable de esta disciplina, y que todo practicante ha de conocer e incorporar en su comportamiento, porque escribe el maestro Tamura: "la etiqueta sirve para controlar el ego que busca siempre satisfacer sus instintos primarios, orientando la energía para utilizarla en el sentido mas positivo o provechoso".

En el ámbito del Budo se concede gran importancia al respeto de las formas, porque es el primer paso para adoptar la mejor disposición en el aprendizaje, y conseguir el mayor provecho en los entrenamientos, y en consecuencia describe el modo de saludar con las manos vacías, con un sable, con un jo, en posición de pie o de rodillas, cómo entrar en el dojo y ubicarse en él, etc. etc.

Merece toda la atención el capítulo en el que expone las diferentes maneras de entrenar, fiel exponente de la riqueza y versatilidad con la que se puede abordar la practica de esta ciencia del movimiento y de la no resistencia, sin agotar nunca las fuentes del descubrimiento personal, en cuanto a la táctica, la estrategia, y la búsqueda de la excelencia en cada acción.

Respecto a los capítulos que tratan de la relación con otras artes marciales, la limpieza y los principiantes, sus textos son tan escuetos que no aportan gran cosa al lector, siendo lo más valioso de ellos las excelentes fotografías que los acompañan.

Dedica unas páginas a los grados, aunque se ciñe a dar una breve reseña histórica, y a las reglas establecidas por el Zaidan Hojin Aikikai, para acceder a los mismos, pero dada la importancia que los aikidokas conceden a este aspecto jerárquico, hubiera sido interesante conocer la opinión y los consejos del maestro Tamura respecto al modo en que hoy se conceden, evaluando sólo la parte física y técnica del candidato, e ignorando si posee o no los valores éticos acordes con el espíritu del Aikido y del Budo.

El capítulo dedicado a los exámenes también merece interés por sus acertados consejos a los candidatos respecto al comportamiento a observar antes, durante y después del examen de Cinto Negro, y también por las excelentes secuencias fotográficas que muestran como recibir un diploma, o una distinción de manos del maestro.

La última parte del libro enseña el modo de atarse el cinturón y vestirse la hakama, así como la manera de plegarla una vez terminado el entrenamiento, y también los cuidados que requiere el mantenimiento de la katana.

Aikido. Etiqueta y Transmisión es un libro escrito por un gran maestro, que se caracteriza por la brevedad y la sabiduría de sus palabras, la experiencia de toda una vida dedicada a la enseñanza de este Arte, y la garantía de ser un testigo directo de sus primeros tiempos, aportando en sus páginas lo mas fundamental de la tradición Budo, como es el respeto y la cortesía en el Dojo, y por extensión en todas las relaciones personales.

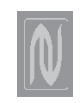

\section{Invitación Al Karate-do (Karate Do Nyu Mon)}

Por Kenwa Mabuni y

Genwa Nakasone

Madrid: Miraguano Ediciones, 2002

208 páginas. $24 \times 17 \mathrm{~cm}$. Ilustraciones

I.S.B.N.: 87-7813-239-2 • $17 €$

Disponible en:

Miraguano Ediciones

C/. Hermosilla, 104

28009 Madrid (España)

Telf.: +34914014645

Fax: +34914021843

E-mail: miraguano@miraguano-sa.es http://www.miraguano-sa.es/

\section{Revisión por Pablo Pereda González}

De encomiable puede calificarse el trabajo de la Editorial Miraguano en su labor de recuperación de obras antiguas sobre Budo, de otro modo inaccesibles al público, como es el caso del libro de referencia escrito por Kena Mabuni, padre del estilo Shito Ryu, y Genwa Nakasone. A este último pocos conocerán por su faceta de editor, redactor y político y sí por su aparición en diversas fotografías con budokas muy conocidos de la época. Quizá la mas conocida y divulgada data del año 36; en ella apa- rece junto a los maestros Kyan, Yabu y Miyagui.

El libro que nos ocupa se compone de dos prólogos; uno del traductor Toshiro Yamaguchi y otro del autor y maestro Mabuni. Lo cierra un epílogo escrito por uno de los hijos del propio maestro: Kenei Mabui. Entre medio 18 capítulos y 55 puntos distribuidos a lo largo de los mismos en cinco partes: "El espíritu Japonés y el Karate-Do”, "El Karate-Do como educación", "Actitud y conocimientos previos a la práctica del Karate-Do", "Ejercicios complementarios y sus instrumentos", y "El Kata Heian Nidan”.

Ya desde el prólogo de Mabuni se deja bien claro el propósito del libro, que no es otro que la difusión del Arte por todo Japón. Funakoshi ya se había establecido allí desde el año 1922 y por tanto el propio Mabubi preparaba su llegada de la mejor manera posible, aunque para ello tuviese que cuestionar al propio Funakoshi por un lado y por otro la propia esencia y origen del Karate-Do. Mabuni hace especial hincapié en las raíces japonesas de la propia Okinawa lo cual, sin duda, pudo generar discrepancias con muchos otros maestros. Todo esto lo puede encontrar el lector en los primeros capítulos del libro.

Llama la atención la actitud de Nakasone en las seis "Consideraciones Preliminares" que aparecen inmediatamente después del prólogo. En un acto de respeto supremo a Mabuni se atribuye toda la responsabilidad sobre los posibles errores que se pudiesen deslizar. Aún permaneciendo el planteamiento confuso, quizá con toda intención, estos posibles errores se refieren a la parte técnica y no a la redacción del pensamiento de Mabuni.

Técnicamente la obra no aporta nada novedoso; tampoco es ese su objetivo, ya que de lo que se trata es dar a conocer un facsímil del año 1938 que servirá, sin duda, como materia de investigación a todos los estudiosos de las raíces del Karate-Do. El aspecto técnico se basa en los Kata "Heian Nidan" y "Sandan", incluyendo sus bunkais, que se desarrollan mediante dibujos a partir del el capítulo 13. Las explicaciones son valiosas dentro del contexto del año en que fue publicado el libro; en el presente son confusas para el neófito; no así las explicaciones teóricas.

El capítulo 18, muy interesante por cierto, versa sobre preguntas formula- 
das al maestro que hoy día todavía pueden ser útiles a muchos practicantes. Si proceden de la inventiva de Mabuni o el propio Nakasone poco importa.

Se echa de menos un mayor detenimiento en cuanto a los interesantes experimentos médicos realizados en los practicantes de Kata, si bien y en descargo de los autores hay que tomar conciencia de que el libro aparece en el año 1938 y los conocimientos médicos eran muy limitados entonces. Por otra parte la obra está dirigida al grueso de practicantes y aficionados de este, entonces, incipiente Arte.

Sin duda merece la pena la amplia colección fotográfica del propio Mabuni que, junto a los pormenores del entrenamiento que se describe en el epílogo, transportan al lector hacia otro tiempo escapando del momento presente. Al menos para mí, con eso, este libro ya tiene sentido y razón de ser.

Curiosamente el Estilo del maestro -Shito Ryu- no aparece en ninguna parte del libro, a excepción del capítulo siete, donde se habla de los dos sistemas más conocidos de Karate-Do. Para ello cita el suyo propio y Goju Ryu no haciendo referencia alguna al Shotokan creado por Funakoshi, auténtico difusor del Arte de Okinawa, que en enero de 1936 lo dio a conocer públicamente en Tokio.

Todos estos extremos, atendiendo a mis cometarios iniciales, hablan -al menos esa es mi impresión- de que este libro fue escrito por un encargo concreto. ¿Con qué fin? Seguramente con el de implantar el Arte en Japón para erradicarlo completamente de Okinawa, cosa que no consiguió el hombre sino la terrible Guerra Mundial del 45. Quizá por ese motivo en ningún momento se habla de las particularidades del Shito Ryu, evitando de ese modo la publicidad personal para un maestro oriundo de una tierra conquistada. Funakoshi gozaba de la amistad de Jigoro Kano y desde el año 1922 vivía en Tokio. ¡Él era intocable!

Aún así Mabuni evita sus referencias. Cuando lo hace se establece una velada pero severa crítica a sus postulados. Con esta técnica Mabuni, sin faltar en ningún momento al respeto, pretende crear una corriente de simpatía hacia las propias autoridades japonesas ya que critica abiertamente los orígenes del Karate-Do mantenidos por Funakoshi. Esa actitud le sirve para mantener una posición plenamente japonesa en aras de poder prender definitivamente en el país del sol naciente. Las críticas, siempre veladas, se realizan también desde el aspecto técnico, indicando el desconocimiento del hijo de Funakoshi de las técnicas de Shuri-Te, limitaciones que el propio Mabuni se encargó de enmendar al aceptarlo como alumno. En honor a la verdad, hay que decir que estos extremos no figuran en el original y sí en el epílogo redactado por uno de los hijos de Mabuni ya muchos años después.

La lectura concienzuda del libro nos aproxima a todos estos aspectos, por supuesto tan interesantes, de cara a la evolución posterior de los propios Estilos.

A tenor de todo lo expuesto es fácil entender la postura de Nakasone en sus consideraciones iniciales. Por supuesto, como ya ambos intuían, las críticas no se hicieron esperar, pero el maestro debía permanecer incólume. Para eso estaba Nakasone a quien, por otra parte, nadie pudo atribuir las veladas críticas a Funakoshi.

En resumen, un buen libro que sin duda merece ser tenido en cuenta para entender la historia del Karate-Do actual y que todo artista marcial independientemente del Estilo o Arte que practique debería tener en su biblioteca.

La figura de Mabuni no es tan lejana, su hijo aunque muy mayor, todavía vive y existen libros específicos sobre el Shito-Ryu pero este, objeto de mi crítica, tiene el sabor de lo antiguo y la magia de alguien que entrena en el makiwara de noche a la luz de una tenue bombilla iluminando su cuerpo.

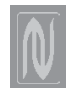

\section{El Tao del Yiquan}

Por Jan Diepersloot

Barcelona: La Liebre de Marzo, 2004

181 páginas. $24 \times 17 \mathrm{~cm}$. Ilustraciones I.S.B.N.: 84-87403-73-5 • $17 €$

Disponible en:

La Liebre de Marzo

Arizala 1, entresuelo 1

08028 Barcelona (España)

Telf.: +34934485605

Fax: +34934498070

E-mail: espejo@liebremarzo.com

http://www.liebremarzo.com/

Revisión por Stuart Kohler
Esta revisión fue publicada en el Journal of Asian Martial Arts vol. 9, $n^{\circ}$ 2, 2000, p. 93, supervisando Juan Pan González la adecuación de la misma a las peculiaridades de la edición de la obra en castellano.

Este volumen es el segundo de la trilogía Warriors of Stillness [Guerreros de la Quietud], que describe el estudio personal del autor acerca de la meditación mediante la quietud y su relación con determinadas artes marciales chinas. El presente volumen recoge el estudio de la meditación en pie (zhanzhuang) y del xingyiquan (el arte marcial de la forma física y la intención mental).

La obra comienza con tres capítulos que muestran una panorámica de la influencia del Budismo en las artes marciales en India y China, junto con la subsiguiente secularización de dichas artes marciales. Esta información se resume principalmente a partir de fuentes convencionales.

Los capítulos 4 y 5 presentan informaciones significativas que no están disponibles en inglés en ningún otro sitio, puesto que el autor cita la práctica totalidad de las escasas fuentes de información existentes en inglés sobre Wang Xiangzhai (1885-1963), el fundador del yiquan. También incluye extractos de los propios escritos de Wang Xiangzhai tal y como fueron traducidos por Fong Ha, haciendo de esta la obra sobre yiquan más completa disponible en el mercado.

Yiquan (literalmente "el arte marcial de la intención mental") es la destilación realizada por Wang Xiangzhai del xingyiquan clásico, quien consideraba que las formas y movimientos complicados eran grandes limitaciones para el desarrollo del artista marcial. Más que entrenar únicamente el cuerpo, Wang Xiangzhai consideraba que el entrenamiento de la mente permitiría que el cuerpo desarrollase la capacidad de reaccionar espontáneamente a cualquier situación sobrevenida. El yiquan se considera un sistema "sin forma" o de "no forma”, que comprende principalmente posturas de meditación en pie.

Los capítulos 6 a 8 introducen elementos de la teoría del yiquan y ejercicios de conciencia, aunque no se deja claro si estos ejercicios son parte del sistema tal como fue creado por Wang Xiangzhai, si fueron ampliaciones realizadas por sus alumnos, o si son contribu- 